10-28-2019

\title{
Social Isolation Among Families Caring for Children With Disabilities
}

Dennis J. Baumgardner

Follow this and additional works at: https://aah.org/jpcrr

Part of the Congenital, Hereditary, and Neonatal Diseases and Abnormalities Commons, Family Medicine Commons, Health and Medical Administration Commons, Medical Humanities Commons, Mental and Social Health Commons, Mental Disorders Commons, and the Pediatrics Commons

\section{Recommended Citation}

Baumgardner DJ. Social isolation among families caring for children with disabilities. J Patient Cent Res Rev. 2019;6:229-32. doi: 10.17294/2330-0698.1726

Published quarterly by Midwest-based health system Advocate Aurora Health and indexed in PubMed Central, the Journal of Patient-Centered Research and Reviews (JPCRR) is an open access, peer-reviewed medical journal focused on disseminating scholarly works devoted to improving patient-centered care practices, health outcomes, and the patient experience. 


\title{
Social Isolation Among Families Caring for Children With Disabilities
}

\author{
Dennis J. Baumgardner, MD | Editor-in-Chief \\ Department of Family Medicine, Aurora UW Medical Group, Aurora Health Care, Milwaukee, WI
}

$\mathrm{I}$ $\mathrm{n}$ this issue of the Journal of Patient-Centered Research and Reviews, Abrams and colleagues explore the stress and burdens of families with a child with oncologic or hematologic disease. ${ }^{1}$ This mixed-methods study identified important themes of logistical and parking issues, financial burden, negotiating the care delivery system, and, importantly, "life disruption and emotional burden." Examples among the latter theme included separation of the involved child and one caretaker family member from the rest of the family, stress involved in ongoing and significant preparation activities, and "emotional turmoil ... which amplifies the other aspects of burden."

A second article published within this issue, by Bedard-Thomas et al, describes the perception of social isolation and loneliness among homebound patients receiving primary care in their places of residence. ${ }^{2}$ Factors leading to social isolation included decreased mobility, inconvenience of travel with assist devices, and reliance on relatives who may have competing demands. $^{2}$

While one could question the generalizability of the findings from these single-institution studies, I suggest that most individuals with personal knowledge of these populations would agree that the identified themes ring true. Further, these works evoke a related issue, that of social isolation among families that include significantly disabled or technologydependent children.

Correspondence: Dennis J. Baumgardner, MD,

Aurora Sinai Medical Center, 1020 N. 12th Street, \#4180, Milwaukee, WI 53233 (dennis.baumgardner@aurora.org)
On this matter I can speak from personal experience as the father of a now young adult with a rare trisomy and a variety of physical and cognitive challenges, including tracheostomyventilator dependence for several years.

This brief editorial will

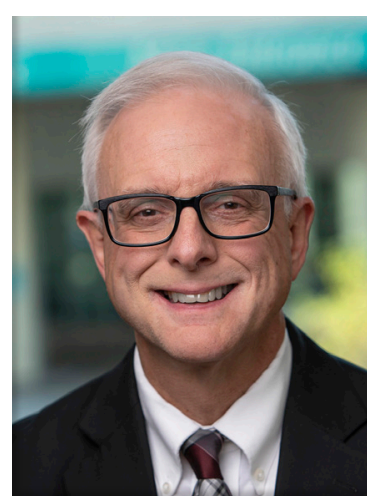
focus on the realities that can cause family isolation. While certainly there are important forms of social isolation of the individual child in various settings - for example, social exclusion from play, frequent absences from school or work (if the child has the opportunity for employment), teasing and bullying, or just wishing to be an "ordinary pupil"3-5 — these will not be specifically discussed here.

\section{Factors Leading to Family Isolation}

Several qualitative studies and reviews have explored family isolation. Mesman and colleagues, in their review of technology dependence on the family, noted the significant impact of social isolation..$^{5}$ Travel is curtailed, as are opportunities for interaction of the involved child with same-aged peers. Prolonged hospitalizations isolate not only the child receiving treatment but other members of the family who are visiting their loved one or "holding down the fort" at home. Siblings may try to avoid public family outings for fear of being embarrassed by the technologydependent brother or sister. ${ }^{5}$ They also may have fewer opportunities for their own peer interactions due to increased household responsibilities, including technical care, in support of their sibling. A focus group study of parents, siblings, and health care workers of 
technology-dependent children receiving home care identified "constraints and inhibitions of normal family functions and family outings, and lack of respite care" in addition to a primary theme of feelings of isolation. ${ }^{6}$

An older review by Kirk noted social isolation of parents, with some who lacked home nursing care for the child becoming essentially homebound. ${ }^{7}$ Specifically emphasized was the difficulty of finding trustworthy individuals willing and able to care for a child with complex medical needs. Also noted was a facet that my wife and I personally experienced, that support from family and friends tends to decrease after hospital discharge. ${ }^{7}$ If in-home nursing care is provided, this provides significant issues of loss of privacy, including inhibition of traditional family interactions and even isolation of parents from one another, because both arguments and signs of affection "within the sight and sound of the professionals in the home" may not properly occur. ${ }^{7}$

Wang and Barnard also reviewed technologydependent children and their families. ${ }^{8}$ Like Kirk, they noted physical and mental "overburden" among parents due to various types of medical care (often delivered by strangers) going on in the home; stress and insomnia from worry, financial concerns, loss of privacy, or triggered medical alarms; and physical exhaustion due to direct care of their child. ${ }^{7,8}$ Clearly, these issues, along with the fear of being away from home when something critical happens, contribute greatly to the inability of affected families to get out for social events or interactions with other families.

\section{Fallout From Family Isolation}

Families react differently when faced with such social disruption. Woolfson pointed out that "how family members perceive and interpret the stresses they experience in parenting a disabled child [may impact] the family's well-being," and that "redefining what constitutes the fulfillment of that need [for social activities or career advancement]" may be an employed coping strategy. ${ }^{9}$

A 2002 study involving interviews of parents of children with disabilities in Israel revealed that while parents were certainly worried about the affected child, they also worried about the social lives and peer interactions of their other children, including the extra burden that might fall on the siblings as a result of their disabled brother or sister. ${ }^{10}$ A majority of the 32 parents believed that they, the parents, were the ones most affected by the child's disability, including changes to their social lives (such as loss of contact with family and friends). Some parents explained that certain friends asked that the child with disabilities not be brought to social events and that their other children tended to not invite their friends home. ${ }^{10}$

Similarly, interviews of parents of children with gastrostomy feeding tubes in the United Kingdom revealed that families felt restricted in their ability to go out for social functions or travel to visit relatives. ${ }^{11}$ These inhibitions resulted from the complexity of and time involved with tube-feeding regimens, significant planning involved in taking the whole family to such things as a movie, and the ability to find the proper place to feed the child other than "in cafés while other people are eating and staring." Some participants even reported that family members found it difficult to be around during tube feedings, and invitations to certain family gatherings were not extended. Isolation of parents from each other also was reported. ${ }^{11}$ In our own personal situation, early on, what energy we as parents had left beyond caring for our disabled child, we put into trying to "normalize" the lives of our other children, rather than seeking out traditional social outings or visits to our home.

A separate mixed-methods study of technologydependent children, siblings, and parents in the United Kingdom noted families' difficulty in committing themselves to regular activities or holidays, the need to schedule activities around times of device-intensive care, and similar aforementioned effects on parents and siblings. ${ }^{12}$ Siblings were sometimes able to provide respite care for the parents to the degree that parents could go out, but sometimes siblings found the need for respite themselves. Single parents were often "particularly socially isolated, having little social life and no employment." 12

Issues of isolation can be magnified in rural areas because of travel distances. ${ }^{13}$ Even if scheduling challenges are overcome, simple outings such as a trip to the playground may be difficult due to layout and equipment not adapted to children who have special needs. ${ }^{14}$ 
In addition to obvious reasons for family social isolation - such as inability to easily move technology or supplies, lack of alternative caregivers for the child (or respite), or in-home appointments and therapies - several less tangible factors, including anxiety or guilt about leaving the child at home while the rest of the family goes out, may contribute. ${ }^{15}$ Some family members are inhibited in social situations by "the upsetting nature of stigmatizing actions/reactions from others." 16 Not only are excursions to visit traditional friends and family members inhibited, but visits by those individuals into the child's home are often curtailed. There are various reasons for this. If there is home nursing or other nonfamily caregivers present in the home, visitors may be uncomfortable with disruptions or perceived lack of privacy. As mentioned earlier, there may be discomfort on the part of the visitors potentially witnessing medical procedures being performed on the child. If the child is present at the table, there may be difficult or open-mouthed chewing, choking spells, or other related behavior exhibited by the child. Wittingly or unwittingly, traditional shared conversations among the visitors in the family may be largely abandoned in favor of discussion surrounding the child with disabilities. Loss of opportunities for previously enjoyed outside social interactions and frequent cancellations may lead previously close friends to drift away from the family.

One other area in which families with children with disabilities experience isolation is in finding a faith community that welcomes, encourages, and includes families who have special needs. Some families express discouragement at the lack of inclusion in such communities and feel that the effort to attend services is not worth the reaction of other members. Those who persist in finding an inclusive community often receive significant emotional support and find positive and meaningful ways to cope with or reframe their family experiences.

\section{Persistence and Encouragement}

Not all is bleak with these families. As in the study of socially isolated adults in this issue, ${ }^{2}$ not all families experience loneliness or are particularly distressed about their relative social isolation. The study by Heiman revealed that 24 of 32 Israeli parents experienced "positive and optimistic feelings of love, joy, and acceptance, as well as satisfaction and strength that accompany success in rearing their special child," despite initial negative reactions to the situation. ${ }^{10}$ Some persevere with overcoming the many barriers and challenges and manage to get out and socialize despite the multiple issues. More recently, technology-assisted virtual social networks may be set up, perhaps including other families caring for children with disabilities, to minimize social isolation. Additionally, I have observed that many communities have set up handicapped-accessible playgrounds and sports programs (eg, Miracle League fields, Special Olympics, local leagues that include children who have special needs) to minimize exclusion of these children and their families.

What can the individual clinician or caregiver who interacts with these families do to further minimize their social isolation? Providing resources and encouragement regarding respite care is important, despite the challenges of initiating these services and reluctance of families to trust stranger-caregivers in this role. ${ }^{15}$ Government-dependent agencies and centers may be recommended for connection to resources, trainings, and support groups, for example, Family Connections in South Carolina (https://www. familyconnectionsc.org/programs-services/). Virtual support networks may be encouraged as well as suggesting persistence in finding that inclusive faithbased community. Many local communities offer family weekends and/or camps for just the child with disabilities, which allows respite for families. There are summer day camps offered through local therapy agencies for children with special needs (and sometimes their siblings) that can give parents much-needed breaks. Local "special needs family" or syndrome groups may sponsor opportunities for parents and families to get together. They also may host "sibling days," which allow siblings the chance to be given a special day and connect with other siblings of children with disabilities.

Finally, we must be aware of the complexity and significant "pragmatics of caregiving"16 inherent in families with children with disabilities. These issues must be acknowledged and ongoing caring encouragement given. Let us all be challenged to reach out to our own social acquaintances who are a part of such families. 


\section{Acknowledgments}

I would like to acknowledge the experiential input (and the loving care of their special children) of my wife, Mary Baumgardner, and daughter, Anne Jones.

\section{References}

1. Abrams HR, Leeds HS, Russell HV, Hellsten M. Factors influencing family burden in pediatric hematology/oncology encounters. J Patient Cent Res Rev. 2019;6:243-51.

2. Bedard-Thomas J, Gausvik C, Wessels J, Regan S, Goodnow $\mathrm{K}$, Goroncy A. I live alone but don't feel alone: social isolation and loneliness from the patient perspective. J Patient Cent Res Rev. 2019;6:262-6.

3. Lindsay S, McPherson AC. Experiences of social exclusion and bullying at school among children and youth with cerebral palsy. Disabil Rehabil. 2012;34:101-9. CrossRef

4. Fagerskiold AM, Mattsson GG. Disabled children and adolescents may be outside is in the community. Int Nurs Rev. 2010;57:470-7.

5. Mesman GR, Kuo DZ, Carroll JL, Ward WL. The impact of technology dependence on children and their families. J Pediatr Health Care. 2013;27:451-9. CrossRef

6. Baumgardner DJ, Burtea ED. Quality-of-life in technologydependent children receiving home care, and their families a qualitative study. WMJ. 1998;98:51-5.

7. Kirk S. Families' experiences of caring at home for a technology-dependent child: a review of the literature. Child Care Health Dev. 1998;24:101-14.

8. Wang KW, Barnard A. Technology-dependent children and their families: a review. J Adv Nurs. 2004;45:36-46. CrossRef
9. Woolfson L. Family well-being and disabled children: a psychosocial model of disability-related child behaviour problems. Br J Health Psychol. 2004;9:1-13. CrossRef

10. Heiman T. Parents of children with disabilities: resilience, coping, and future expectations. J Devel Phys Disabil. 2002;14:159-71. CrossRef

11. Brotherton AM, Abbott J, Aggett PJ. The impact of percutaneous endoscopic gastrostomy feeding in children; the parental perspective. Child Care Health Dev. 2007;33:539-46. CrossRef

12. Heaton J, Noyes J, Sloper P, Shah R. Families' experiences of caring for technology-dependent children: a temporal perspective. Heath Soc Care Community. 2005;13:441-50. CrossRef

13. Walker A, Alfonso ML, Colquitt G, Weeks K, Telfair J. "When everything changes:" parent perspectives on the challenges of accessing care for a child with a disability. Disabil Health J. 2016;9:157-61. CrossRef

14. Prellwitz M, Skär L. Usability of playgrounds for children with different abilities. Occup Ther Int. 2007;14:144-55. CrossRef

15. Yantzi NM, Rosenberg MW, McKeever P. Getting out of the house: the challenges mothers face when their children have longterm care needs. Heath Soc Care Community. 2007;15:45-55. CrossRef

16. Green SE. "We're tired, not sad": benefits and burdens of mothering a child with a disability. Soc Sci Med. 2007;64:150-63. $\underline{\text { CrossRef }}$

(C) 2019 Aurora Health Care, Inc. 